\title{
Investigating food preference in zoo-housed meerkats
}

\author{
Bridget W. Brox ${ }^{1}$ (i) | Katheryn Edwards ${ }^{2}$ | Natasha A. Buist ${ }^{2}$ | Anne C. Macaskill ${ }^{2}$
}

${ }^{1}$ Department of Animal Science, Wellington Zoo Trust, Wellington, New Zealand

${ }^{2}$ School of Psychology, Victoria University of Wellington, Wellington, New Zealand

Correspondence

Bridget W. Brox, Department of Animal Science, Wellington Zoo Trust, 103 Downing St, Crofton Downs, Wellington 6035, New Zealand.

Email: bridget.brox@gmail.com

\begin{abstract}
Understanding food preference among animals in human care can support improvements to welfare through training and day-to-day care (e.g., diet management). Little has been published about food preference in zoo-housed meerkats. Assessing meerkat food preference would be useful, not only for the welfare of that species, but also for developing approaches to assessing food preference in other grouphoused, social species. The specific aim of this study was to quantify food preference within the meerkat mob at Wellington Zoo. We developed a simple, cost-effective method for characterizing the food preference hierarchy in meerkats by presenting pairs of foods to the mob as a group. We observed stable preference with the hierarchy for pups closely resembling that for adults. This study demonstrated that it is possible to assess food preference and identify a food preference hierarchy for a group of animals from a social species where it was neither practical nor appropriate to assess individuals' preferences separately.
\end{abstract}

\section{KEYWORDS}

animal welfare, food preference, meerkat

\section{1 | INTRODUCTION}

Food preference testing in zoos (and other institutions where animals receive care from humans) has wide-ranging implications for the individual animals, their cohorts, and larger species groups. Researchers evaluate preference by presenting two foods concurrently and evaluating which the animal selects (Clay et al., 2009; Gaalema et al., 2011; Mehrkam \& Dorey, 2015). A good understanding of food preference facilitates the identification of effective reinforcers to support training (Fernandez et al., 2004; Martin et al., 2018), improves husbandry practice (Addessi et al., 2005; Alligood et al., 2017; Naves et al., 2017), and supports overall welfare (Mehrkam \& Dorey, 2015; Steele et al., 1995). While nonfood reinforcers can be used to train animals (e.g., for general husbandry and health checks) food is often a powerful motivator and several research groups have undertaken studies to understand what food items best serve as reinforcers for species or individual animals in human care (Clay et al., 2009; Gaalema et al., 2011).

A range of studies has demonstrated the utility of directly assessing animals' food preferences by offering food alternatives and observing eating patterns (Bacon \& Burghardt, 1983; Carter et al., 1999; Cunha et al., 2015; Nowakowski et al., 2006; Rao et al., 2018; Roberts \& Mitchell, 1998; Unger \& Schratter, 2000). Importantly, none of these studies has looked at groups of animals and, in general, methods for evaluating food preference on a group level have not been developed. In one exception to this, Remis (2002) conducted preference assessments with the same group of gorillas both individually and as a group. Different foods were tested in each context, however, both approaches produced clear food preference hierarchies and preference had similar factor structures with factors relating to the nutritional content of the food (Remis, 2002). This suggests that group preference assessments might be a feasible approach.

Other studies have investigated the complex interplay between food preference and specific nutrients in food items (Kawata \& Elsen, 1992; Lalremruati \& Solanki, 2018). It was initially proposed that animals will seek out specific essential nutrients because it is adaptive to do so; however, food preference studies demonstrate that most species do not seek out essential nutrients but instead choose food items according to other properties like carbohydrates, 
total energy, and crude protein (Alvarez \& Kravetz, 2009; Jildmalm et al., 2008; Laska et al., 2000; Remis, 2002; Zoidis \& Markowitz, 1992). These results also demonstrate that it remains necessary to directly assess food preference for a given species; it is not currently possible to deduce preference hierarchies from nutritional analyses of food alone.

The current study developed a method to investigate food preference in group-housed slender-tailed meerkats (Suricata suricatta). Wild meerkats live in groups of up to forty individuals where a dominant female produces most offspring. This highly social species collaborate to: obtain food via foraging; build tunnels (for sleeping at night and to avoid predators during the day); protect the mob (alternating sentry duty where one meerkat watches for danger); and rear the young (Bousquet, 2011; Ross-Gillespie \& Griffin, 2007).

Meerkats learn about food socially. A "demonstrator" meerkat can learn a foraging task and then teach it to other members of the mob (Hoppitt et al., 2012; Thornton \& Malapert, 2009). Thornton (2008b) demonstrated that meerkats teach pups to capture and kill prey; as pups gain proficiency, they are taught to engage with more and more difficult prey items such as live scorpions. Pups able to engage with the item alongside another meerkat were more likely to approach and consume it (Thornton, 2008a).

The highly social nature of meerkats' food-related behaviors suggests that it is ideal to examine the preference of the mob as a group. Conducting a group-level preference assessment was also necessary because the mob of zoo-housed meerkats we worked with could not be tested individually for practical and welfare reasons including concern about reintroduction of individuals to the group following testing. Most studies have tested animals individually even if species normally live in groups. Individual food-preference testing has the advantage of identifying an individual's idiosyncratic preferences (Carter et al., 1999; Clay et al., 2009; Cunha et al., 2015); however, many animals in human care live in groups and cannot reasonably be separated for individual testing. The current study therefore developed an approach for testing social, group-housed species as a group, providing a unique window into food preference in highly social species with implications for other species that live in groups.

We expected to observe a graded preference hierarchy in which foods could be ranked from most to least preferred. Additionally, if our novel group-based method successfully characterized meerkats' preferences, we expected that when given a choice between two foods, meerkats would choose the one higher in the hierarchy, consistent with the idea that food preference is transitive (Addessi et al., 2008; Moermond \& Denslow, 1983). Transitive preference means that if food $A$ is preferred to food $B$ and food $B$ is preferred to food $C$ then food $A$ will be preferred to food $C$.

As yet there are no studies testing meerkats' food preferences as a group. One unpublished study (Salomonsson, 2011) examined food preference in zoo-housed meerkats but the meerkats were tested individually. Meerkats preferred insect food items (i.e., crickets) and those high in protein. Most meerkats demonstrated a similar pattern of food preference to the dominant female and the author suggested that food preference may be transmitted from mother to offspring.

The specific aim of this study was to quantify food preference in a mob of zoo-housed meerkats and to determine whether their food preference choices indicated a stable, consistent preference hierarchy. We used a paired-choice preference assessment (Fisher et al., 1992) and analyzed the preferences of pups and adults separately. A secondary aim was to develop and test a brief, practical method for examining food preference in social group-housed zoo species.

\section{2 | MATERIALS AND METHODS}

\section{1 | Group makeup}

The mob consisted of 12 slender-tailed meerkats (Suricata suricatta). Figure 1 presents the birthdates and relationships of these 12 (other meerkats had previously resided in the habitat with older members of this mob but were no longer present at the time of the study). The eldest meerkat (dominant female) was born in 2012 at Wellington Zoo and has continuously resided in the habitat space where the study took place. Two adult males (born in 2013) were transferred from Twycross Zoo (Atherstone, England) in 2015 where they were housed together. After arriving at Wellington Zoo, they were integrated into the existing meerkat mob. The remaining nine individuals comprise the last four litters produced by the dominant female. The three meerkats born in July 2018 were still juveniles during the time of the study.

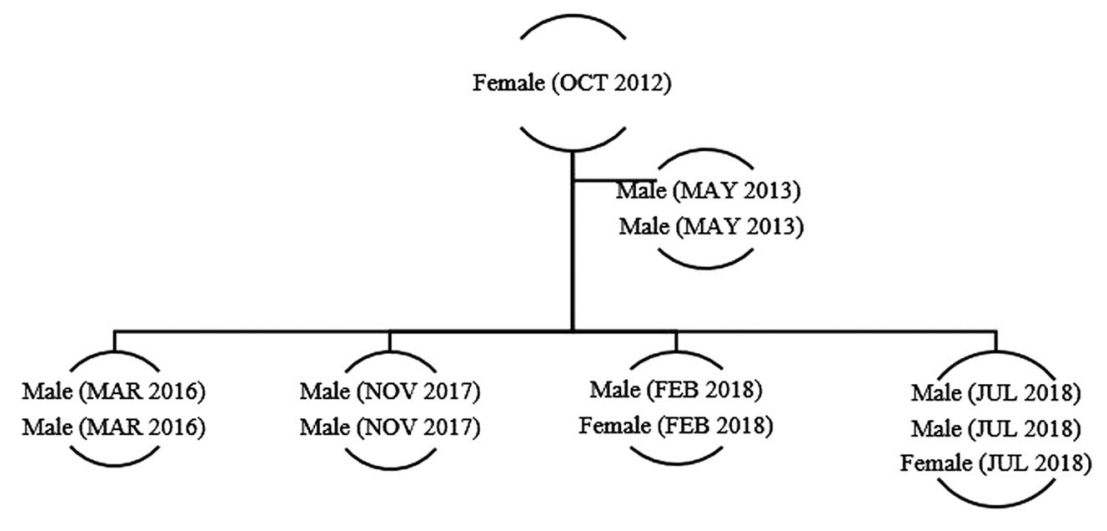

FIGURE 1 Meerkat mob breakdown including sex, birthdate, and relationship to the dominant female 


\section{2 | Study location}

The study was conducted in a mixed-species habitat that housed the meerkat mob and a pair of African crested porcupines (Hystrix africaeaustralis). As the study was conducted during the day, and African Crested Porcupines are primarily nocturnal, the porcupines did not interact with the mob during testing. The habitat space $\left(18 \times 6 \mathrm{~m}^{2}\right)$ was enclosed by a 2-m boundary wall with several viewing windows adjacent to the visitor space. The space was interspersed with furniture (pieces of browse, rotten logs, and small trees) as well as a variety of substrates (bark chip, lime sediment) to encourage natural behaviors such as foraging and digging. There were three dens each with a viewing window. Water was available in the habitat ad libitum (this included during the study).

Researchers conducted all experimental trials in the center of the habitat space near one of the viewing windows. This allowed one researcher to work inside the habitat (placing and then collecting food items) while two others worked outside the habitat (timing, recording video data, and resetting between trials).

\section{3 | Food preference testing}

All aspects of this study were reviewed and approved by the Victoria University of Wellington Animal Ethics Committee.

Food preference testing was undertaken from September 17 to 28 , 2018. Before commencing this study, a list of food items was approved for use by the Wellington Zoo Nutrition Advisor (Table 1). All food items were prepared before testing ( $65 \mathrm{ml}$ per volume); each item was cut into approximately $0.5 \times 0.5 \mathrm{~cm}^{2}$ pieces. There were always substantially more than 12 pieces provided and thus more than one piece available per mob member.

There were 66 unique pairs of foods, 41 of which were tested. One of our goals was to develop a time-effective method, therefore, rather than comparing every pair, in later sessions, we selected pairs of items that would most help us clarify and refine the preference hierarchy (see below). We conducted five trials during the first session, presenting the first 10 foods listed in Table 1 in random pairs. Following the first session, it was evident that it was practical to conduct additional trials in a session without satiating the meerkats or overloading the time of zoo staff. Therefore, we conducted 12 trials during each of three additional sessions. During sessions 2-4, each food was presented two times (unlike in session 1 when they were each presented only once). Therefore, during sessions 2-4, timing and location of presentation were counterbalanced so that each food was presented once during the first six trials and once during the second six trials; each food was presented once on the left and once on the right (Salomonsson, 2011 observed side biases). During sessions 2 and 3, pairs were selected at random within the constraints described above. During the fourth session, the 12 pairs of foods were selected to provide the most information possible about the preference hierarchy. Based on observations in the first three sessions, we were able to approximately divide the foods into a
TAB LE 1 Wellington Zoo Nutrition-Advisor-approved food items used in this study and how they were prepared

\begin{tabular}{ll} 
Food item & Preparation \\
\hline Horse meat & Raw, chopped \\
\hline $\begin{array}{l}\text { Chicken } \\
\text { Hill's science diet adult light } \\
\text { (dry cat biscuit) }\end{array}$ & Raw, chopped \\
\hline Grape & Rone \\
\hline Pear & Raw, chopped \\
\hline Vegetable mix (carrot/pea/corn) & Raw, chopped \\
\hline Pumpkin (flesh) & Raw, thawed \\
\hline Pumpkin (seeds) & Raw, peeled, chopped \\
\hline Cauliflower & Raw, pumpkin flesh removed \\
\hline Broccoli & Raw, chopped \\
\hline Banana & Raw, chopped \\
\hline Egg & Raw, peeled, chopped \\
\hline
\end{tabular}

higher preference category (eggs, chicken, banana, horse, pear, and grape) and a lower preference category (cat biscuits, pumpkin seeds and pulp, broccoli, and corn mix). To further refine the preference hierarchy, all pairs presented during the fourth session consisted of two items from the same category. Pairs were randomly determined within each category. During the fifth session, we presented six randomly presented foods (corn mix, pumpkin seeds, cauliflower, pear, chicken, and horse) with the same food on each side ${ }^{1}$ to assess whether meerkats showed a side bias toward one container location over the other.

Each session was completed between 0800 and 1000 before the regular morning feed; ensuring that the mob was non-satiated during food preference testing. There were typically no zoo visitors present during sessions. Immediately after testing the regular morning diet item was provided to the mob; despite engaging with the food preference items the mob readily consumed this diet item. This suggested that it was unlikely that later food preference trials were affected by satiation from food eaten during earlier trials. Throughout the sessions, meerkats were free to engage with the food presented, or to move to any other area of the habitat.

During each food preference trial, two food items were placed on low profile plastic containers $\left(35 \times 35 \mathrm{~cm}^{2}\right)$; clear plastic lids $(13 \mathrm{~cm}$ tall) were secured with one of two latches at the base of the container (see Figure 2). The two containers were placed on the ground approximately $1 \mathrm{~m}$ apart in the front of the habitat space (Figures $2 \mathrm{a}$ and $2 \mathrm{~b}$ ). When the containers were placed on the ground two researchers outside the habitat commenced timing the trial and recording video. The mob was given $30 \mathrm{~s}$ to explore the outside of the containers (Figure 2c); this provided an

${ }^{1}$ During a fifth session, we also examined preference for $5 \mathrm{MK} 8$ insectivore pellets. We removed analysis of these conditions following consideration of reviewer comments, but results are available from the first author upon request. 
opportunity for the meerkats to explore both containers while the amount of food remained consistent, provided a non-consummatory preference test (see Thompson et al., 2016), and reduced the likelihood of satiation. Thompson et al. tested one pair of foods and found that dogs directed more behavior toward the inaccessible food that they later preferred in a consumption test. This suggests that inaccessible food tests could assess animals' food preferences without disrupting their zoo prescribed diets. Thompson et al. did not assess whether inaccessible food preference testing would accurately characterize a larger preference hierarchy; we evaluated this in the current study.

The containers may have restricted the meerkats' ability to detect foods by scent; we tested this by analyzing preference during this phase separately (see below). If inability to smell the food prevented meerkats from identifying their most preferred food, then the hierarchy determined from this phase would be inconsistent with that determined from the consummatory preference test conducted next.

The experimenter inside the habitat began removing lids after $30 \mathrm{~s}$ (Figures $2 \mathrm{~d}$ and $2 \mathrm{e}$ ). The left lid was removed first on half the trials and the right lid was removed first on the remaining half. From video data (see below) the median time between the lids being removed was $4.55 \mathrm{~s}$. The experimenter then returned to her station standing still between the two containers. The mob then had 2 min to engage with the food items (Figure 2f). There was enough room around each container for approximately eight meerkats to feed simultaneously. After 2 min, the containers were removed from the habitat space; their surfaces were wiped down with water and the next pair of food items was staged. Due to the enthusiasm of the mob, we found it necessary for the experimenter inside the habitat to use a small shield to protect his/her hand when removing the lids from the containers.

\subsection{Data analysis}

We coded videos of each food-preference trial to quantify the meerkats' engagement with each food item. The first sampling point was when both containers were on the ground and the experimenter

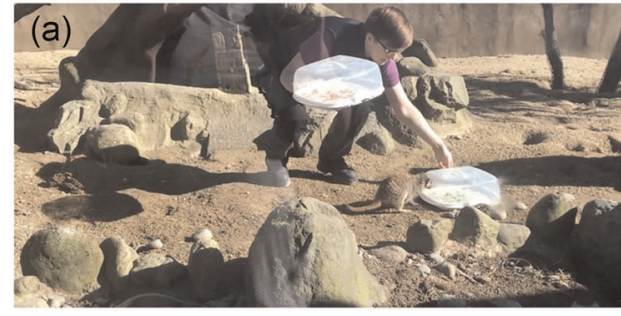

Experimenter places first lidded container on ground

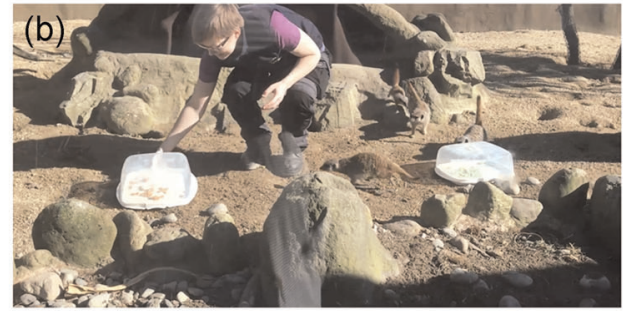

Experimenter places second lidded container on ground

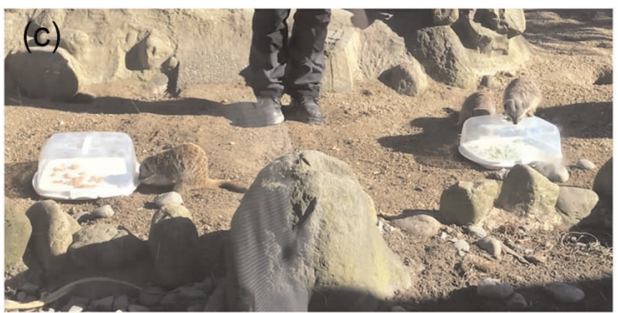

Experimenter stands motionless between the containers for 30 s

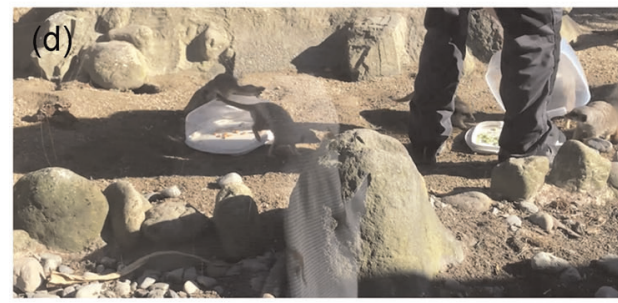

Experimenter removes first lid

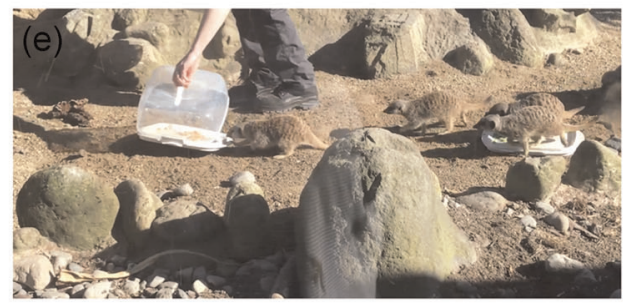

Experimenter removes second lid

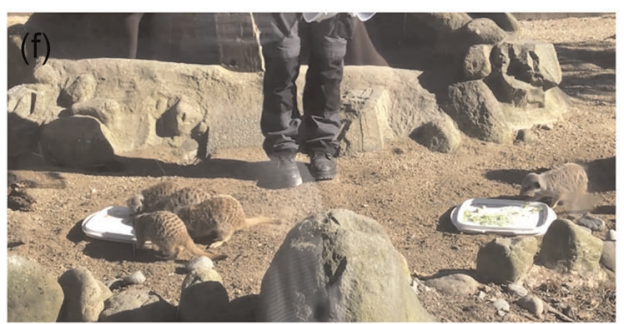

Experimenter stands motionless between the containers for $120 \mathrm{~s}$

FIGURE 2 Procedure for each food-preference trial (sides counterbalanced) [Color figure can be viewed at wileyonlinelibrary.com] 
TABLE 2 Food preference hierarchies for meerkats

\begin{tabular}{|c|c|c|}
\hline $\begin{array}{l}\text { Food inaccessible } \\
(30 \mathrm{~s})\end{array}$ & $\begin{array}{l}\text { Food accessible } \\
\text { (first } 30 \mathrm{~s} \text { ) }\end{array}$ & $\begin{array}{l}\text { Remainder of } \\
\text { the trial }(120 \mathrm{~s})\end{array}$ \\
\hline $\begin{array}{l}\text { Hard-boiled } \\
\text { eggs (2.89) }\end{array}$ & Hard-boiled eggs (5.7) & Pumpkin pulp (3.09) \\
\hline Banana (2.84) & Grape (4.98) & Banana (2.65) \\
\hline Horse (2.69) & Banana (4.81) & Pear (2.06) \\
\hline Pumpkin pulp (2.6) & Pear (4.19) & Grape (1.99) \\
\hline Chicken (2.57) & Pumpkin pulp (3.79) & $\begin{array}{l}\text { Corn, peas carrot } \\
\operatorname{mix}(1.61)\end{array}$ \\
\hline Grape (2.53) & $\begin{array}{l}\text { Corn, peas carrot } \\
\operatorname{mix}(3.18)\end{array}$ & $\begin{array}{l}\text { Hard-boiled } \\
\text { eggs (1.39) }\end{array}$ \\
\hline Pear (2.42) & Horse (2.89) & Chicken (0.9) \\
\hline Cauliflower (2.23) & Chicken (2.76) & Cat biscuits (0.84) \\
\hline Broccoli (2.1) & Cat biscuits (1.73) & Cauliflower (0.6) \\
\hline Cat biscuits (1.89) & Cauliflower (1.09) & Horse (0.54) \\
\hline Pumpkin seeds (1.82) & Broccoli (0.98) & Broccoli (0.54) \\
\hline $\begin{array}{l}\text { Corn, peas carrot } \\
\text { mix (1.8) }\end{array}$ & Pumpkin seeds (0.91) & Pumpkin seeds (0.45) \\
\hline
\end{tabular}

Note: Foods are listed from most to least preferred. Numbers in parentheses are the mean number of meerkats engaged with each food.

had returned to her station in between the two food containers. We then sampled the data every $5 \mathrm{~s}$. At each sampling point, we counted the number of adults and pups at each container. While the lids were on the containers, we counted meerkats that were (1) oriented with their head toward the container and, (2) with their head less than their own body length from the container. We used their own body length to determine whether they were close enough to the container to be engaging with it because this was a readily available metric and customized the distance the size of the individual meerkat.

We coded the time at which each lid was removed (defined as the lid physically separating from the carrier base). Coding of meerkat numbers continued at $5 \mathrm{~s}$ intervals from the removal of the second lid until the end of the trial. When the lids were removed, we counted meerkats that were (1) oriented toward the food with their heads down and (2) with their head less than half their own body length from the container.

At the end of each trial, we recorded whether the food was left on the container lid or not. We also recorded the approximate time that either food was completely consumed if this occurred within the 2 min window. This time was approximate because on a small but non-zero number of trials it was difficult to visually determine whether all food was consumed, particularly as meerkats often tracked sand from the habitat onto the container lids. Of all foods presented, 74 (69.8\%) had some leftover at the end of the trial while 32 (30.2\%) were entirely consumed. The minimum time it took for the food to be marked as cleared was $54 \mathrm{~s}$, and the maximum $159 \mathrm{~s}$. Given that some foods were likely consumed unevenly across the trial, the number of meerkats eating each food later in the trial might have reflected differences in the amount of each food available following earlier consumption, which might not be indicative of preference when equal quantities were available. To investigate this possibility, we used an ANOVA to test whether there was an effect of trial timepoint on the mean number of meerkats engaged with each food.

We first ranked the foods from least to most preferred based on the mean number of meerkats choosing them across all trials on which that food was presented. We then examined how many individual pairs of foods indicated preference consistent with the overall hierarchy. We also tested how well preference on each trial was predicted by the hierarchy on all other trials without that trial included.

\section{3 | RESULTS}

\subsection{Changes in number of meerkats engaging with food during trials}

We first characterized the mob's preference hierarchy by ranking the foods based on the mean number of meerkats present when food was inaccessible (30 $\mathrm{s}$ when lids were covering the food), when it was first made accessible ( $30 \mathrm{~s}$ after the lids were removed), and for the remainder of the trial. Observations after a food was completely eaten were not used when constructing the "remainder of the trial" hierarchy. The mean number of meerkats engaged with each food item across all trials is presented in Table 2.

A one-way ANOVA indicated a significant effect of trial time point on the mean number of meerkats engaged with each food $(F(2)=13.0, p<.001)$. Follow-up $t$-tests indicated that there was no difference between the number of meerkats engaged with each type of food before and after lid removal $(t(1)=1.8, p=.101$, but fewer were engaged during the latter part of the trial than earlier when the foods were inaccessible $(t(11)=4.24, p=.001)$ or accessible $(t(11)=4.94, p<.001)$. This pattern suggested that after $30 \mathrm{~s}$ the amount of food available began to diminish to the point that fewer meerkats were engaged with the food, and, therefore, that the first $30 \mathrm{~s}$ after the food was available is a more appropriate window during which to assess food preference of the group as a whole.

\subsection{Consistency of preference hierarchy}

We established how consistent the hierarchies were at each time point by determining the correlations between the numbers of individuals engaging with each food at each of the three time points. Hierarchies are given in Table 2. There were strong correlations between the hierarchies as assessed when food was inaccessible and first accessible $(r(10)=0.733, p=.007)$, and the hierarchies when food was first accessible and during the rest of the session $(r(10)=0.720, p=.008)$, but the correlation between the hierarchies as assessed when food was inaccessible and during the final 2 min of the trial did not reach significance $(r(10)=0.454, p=.138)$. 
We evaluated how consistently the group preferred higherranked items to lower-ranked when the foods were inaccessible (Figure 3) and when they were accessible (Figure 4). We did not assess the consistency of the preference hierarchy during the remainder of the session due to the significant drop in the number of meerkats engaging with all foods during this time. When foods were inaccessible, 32/41 pairs (78\%) were consistent with the overall hierarchy (with equal preference on two trials). During the first $30 \mathrm{~s}$ that both foods were available, this number rose to $35 / 41$ or $85 \%$ (with equal preference on three trials). The three instances in which the lower-ranked food on the hierarchy were preferred for pairs close together on the hierarchy.

We used all trials to establish the hierarchy, and then used that hierarchy to predict preference on each individual trial. Thus, the trial predicted was included in the set used to establish the hierarchy, potentially inflating the apparent accuracy of predictions. To assess this, we predicted preference on each trial from the hierarchy derived from all other trials, with the predicted trial excluded. Before foods were accessible, hierarchies established without the food on a given trial included were notably worse predictors of preference on that trial, with only $24 / 41$ (58\%) of predictions accurate. However, when foods were accessible predictions were just as accurate when the predicted trial was excluded, with 35/41 trials predicted accurately. The side preferred during trials where we presented the same food on each side are presented in the diagonal. There was no evidence of a consistent side bias. Thus, location bias is unlikely to account for the (rare) trials on which the group preferred a lower-ranked food.

\subsection{Consistency of preference hierarchies across group members}

We examined the similarity between the hierarchies for the three juvenile meerkats and the adults during the first $30 \mathrm{~s}$ after the lids were removed. Hierarchies for adults and juveniles are presented in Table 3. The hierarchy for the adults was identical to that for the whole group. The hierarchy for juveniles was similar but not identical. The correlation between the mean numbers of adults and juveniles engaged with each food was high $(r(11)=0.762, p=.004)$.

\section{4 | DISCUSSION}

Results of the study demonstrate that it is possible to characterize a consistent preference hierarchy for a group-housed species in a relatively small number of trials. Cooked eggs and raw meat rose to the top of the hierarchy, which is perhaps unsurprising given the meerkats' primarily carnivorous wild diet. Salomonnsson (2011) conducted the only previous study of food preference in meerkats. Meerkats were tested individually, and a different set of foods was tested. Nevertheless, there are some similarities in findings. Both studies suggested that vegetables tended to be low on the hierarchy, and with eggs higher up. Salomonsson included insects in their food preference testing, and found they were highly preferred along with other high-protein foods including egg white (consistent with our finding that whole boiled eggs were highly preferred).

\begin{tabular}{|c|c|c|c|c|c|c|c|c|c|c|c|c|}
\hline & $\begin{array}{l}\text { corn, } \\
\text { peas } \\
\text { carrot } \\
\text { mix }\end{array}$ & $\begin{array}{l}\text { Pumpkin } \\
\text { seeds }\end{array}$ & $\begin{array}{l}\text { Cat } \\
\text { biscuits }\end{array}$ & Broccoli & Cauliflower & Pear & Grape & Chicken & $\begin{array}{l}\text { Pumpkin } \\
\text { pulp }\end{array}$ & Horse & Banana & $\begin{array}{l}\text { Hard } \\
\text { boiled } \\
\text { eggs }\end{array}$ \\
\hline $\begin{array}{l}\text { corn, peas } \\
\text { carrot mix }\end{array}$ & $\mathrm{L}$ & & $\leftarrow$ & & & & & & & & & \\
\hline $\begin{array}{l}\text { Pumpkin } \\
\text { seeds }\end{array}$ & & $\mathrm{R}$ & & $=$ & & & & $=$ & & & & \\
\hline Cat biscuits & & & & & $\leftarrow$ & & & & & & & \\
\hline \multicolumn{13}{|l|}{ Broccoli } \\
\hline Cauliflower & & & & & $\mathrm{L}$ & & & & & & & \\
\hline Pear & & & & & & $\mathrm{R}$ & & $\leftarrow$ & $\leftarrow$ & & & \\
\hline Grape & & & & & & & & & $\leftarrow$ & & & \\
\hline Chicken & & & & & & & & $\mathrm{L}$ & & & & \\
\hline $\begin{array}{l}\text { Pumpkin } \\
\text { pulp }\end{array}$ & & & & & & & & & & $\leftarrow$ & & \\
\hline Horse & & & & & & & & & & $R$ & & $\leftarrow$ \\
\hline Banana & & & & & & & & & & & & \\
\hline
\end{tabular}

FIGURE 3 Preference hierarchy for the group while foods were inaccessible is given in the top row (least-to-most preferred left-to-right) and the first column. Right arrows indicate a pair of foods for which the group preferred the higher food item in the hierarchy. Left arrows indicate a pair of foods for which the group preferred the lower item in the hierarchy. $L$ and $R$ in the diagonal indicate whether the group preferred the left or the right container when both contained the same food 


\begin{tabular}{|c|c|c|c|c|c|c|c|c|c|c|c|c|}
\hline & $\begin{array}{l}\text { Pumpkin } \\
\text { (seeds) }\end{array}$ & Broccoli & Cauliflower & $\begin{array}{c}\text { Cat } \\
\text { biscuits }\end{array}$ & Chicken & Horse & $\begin{array}{l}\text { corn, peas } \\
\text { carrot mix }\end{array}$ & $\begin{array}{l}\text { Pumpkin } \\
\text { pulp }\end{array}$ & Pear & Banana & Grape & $\begin{array}{c}\text { Hard } \\
\text { boiled } \\
\text { eggs }\end{array}$ \\
\hline $\begin{array}{l}\text { Pumpkin } \\
\text { seeds }\end{array}$ & $\mathrm{L}$ & $\leftarrow$ & & & & & & & & & & \\
\hline \multicolumn{13}{|l|}{ Broccoli } \\
\hline Cauliflower & & & $\mathrm{R}$ & & & & & & & & & \\
\hline Cat biscuits & & & & & & & & & & & $=$ & \\
\hline Chicken & & & & & $\mathrm{R}$ & $\leftarrow$ & $\leftarrow$ & & & & & \\
\hline Horse & & & & & & $\mathrm{L}$ & $=$ & & & & & \\
\hline $\begin{array}{l}\text { corn, peas } \\
\text { carrot mix }\end{array}$ & & & & & & & L & & & $=$ & & \\
\hline \multicolumn{13}{|l|}{$\begin{array}{l}\text { Pumpkin } \\
\text { pulp }\end{array}$} \\
\hline Pear & & & & & & & & & $=$ & & & \\
\hline Banana & & & & & & & & & & & & \\
\hline Grape & & & & & & & & & & & & \\
\hline
\end{tabular}

FIGURE 4 Preference hierarchy for the group while foods were accessible is given in the top row (least-to-most preferred left-to-right) and the first column. Right arrows indicate a pair of foods for which the group preferred the higher food item in the hierarchy. Left arrows indicate a pair of foods for which the group preferred the lower item in the hierarchy. 41/47 (87\%) pairs assessed were consistent with the overall hierarchy. $L$ and $R$ in the diagonal indicate whether the group preferred the left or the right container when both contained the same food. In the bottom left half of the table arrows pointing down indicate that the choice of the dominant female was consistent with the preference hierarchy for the rest of the group

TAB LE 3 Hierarchies for juvenile (left column) and adult (right column) meerkats

\begin{tabular}{ll}
$\begin{array}{l}\text { Food preference hierarchy } \\
\text { for juvenile meerkats }\end{array}$ & $\begin{array}{l}\text { Food preference hierarchy } \\
\text { for adult meerkats }\end{array}$ \\
\hline Pumpkin pulp (1.23) & Hard boiled eggs (5.37) \\
\hline Banana (1.11) & Grape (4.58) \\
\hline Grape (1.03) & Banana (4.37) \\
\hline Corn, peas carrot mix (1) & Pear (3.89) \\
\hline Pear (0.91) & Pumpkin pulp (3.19) \\
\hline Hard boiled eggs (0.9) & Corn, peas carrot mix (2.67) \\
\hline Cat biscuits (0.75) & Horse (2.6) \\
\hline Horse (0.69) & Chicken (2.58) \\
\hline Chicken (0.49) & Cat biscuits (1.38) \\
\hline Broccoli (0.43) & Cauliflower (0.93) \\
\hline Pumpkin seeds (0.36) & Broccoli (0.88) \\
\hline Cauliflower (0.36) & Pumpkin seeds (0.73) \\
\hline
\end{tabular}

Note: The mean number of individuals engaging with the food is given in parentheses.

Results suggest that first providing opportunity to view, and potentially to smell, the foods but then assessing the hierarchy during a brief window during which both foods are accessible facilitated characterization of the preference hierarchy (see Bacon \& Burghardt, 1983, for a similar approach). Differences between the number of meerkats engaged with the different foods were less extreme when foods were inaccessible. Meerkats' locations during this time might have reflected a combination of exploration and food preference. Additionally, some meerkats might have been unable to distinguish the foods reliably because the container lids occluded scent cues. Overall, however, results suggest that preference testing with inaccessible foods provided a reasonable approximation of the groups' preference hierarchy, consistent with the finding of Thompson et al. (2016) with one food pair with individual dogs.

One goal of the current study was to develop a practical, efficient approach of evaluating a preference hierarchy in a group-housed species. There were some potential limitations of the procedure: for example, we did not test every pairwise combination of foods, and the presence of the meerkats necessitated some trial-to-trial variability in the timing of trial events. These features also make the procedure faster and simpler to implement, likely making it easier to implement in zoos, and, a stable preference hierarchy emerged even given these limitations. Note also that testing the remaining pairs would have been very unlikely to add any additional information, because these remaining pairs were very far apart on the hierarchy. Previous studies found that zoo staff members can be trained to conduct efficient and accurate preference assessments for animals including the preference for enrichment activities in Galapagos tortoises (Mehrkam \& Dorey, 2014), and food items in cotton-top tamarins (Fernandez et al., 2004). The current results suggest that the procedure we developed might similarly be used by zoo staff to assess food preference in meerkats and other group-housed species. 
During preference testing, animals could freely move around the habitat space. This was preferable for their welfare but meant we could not standardize the distance between the meerkats and the food containers or guarantee that every member of the mob was present and attending during every trial. Most individuals were, however, present and engaged at the beginning of each trial. The meerkats were also able to leave the area rather than eat either food, and this was captured in the mean numbers of individuals we used to construct the preference hierarchy, likely making estimates of food preference more accurate.

As Mehrkam and Dorey (2014) noted, in group-housed species, it is difficult to determine the extent to which food preferences reflect social facilitation and/or competition in addition to or instead of individuals' food preferences. Competition is a particular factor for meerkats due to their dominance hierarchy (Ross-Gillespie \& Griffin, 2007). At the current zoo, meerkats were always housed together and fed as a group. Therefore, if competition did affect meerkats' food selections, it would likely do so in all situations in which zoo staff worked with the meerkats. In future food preference studies, it might be useful to ensure that the factors that might affect food preference are held constant between preference testing and husbandry or welfare contexts in which food preference information might be applied, as in the current study.

An additional effect of the group-based preference testing was that preferred foods were depleted faster earlier in the trial meaning that later in the trial the two alternatives were no longer equal in amount. We addressed this issue by using patterns earlier in the trial as our primary index of food preference. We also excluded portions of all trials in which one food had been entirely consumed. However, it was not always possible to determine when this had occurred. Using colored containers that contrasted more strongly with the foods might help address this. For some highly preferred foods, like hard-boiled eggs, we observed that one or two meerkats would remain scouring the container lids for every last trace of egg which likely made these items appear less preferred than they were in reality during the latter part of the session. Additionally, our results suggest that food preference testing could be expedited by conducting shorter trials.

While the overall hierarchy appears accurate, there are features of the procedure that might have caused us to underestimate the extent of preference for the most preferred item in the pair. It is possible that the mob's dominance hierarchy, and interindividual competition meant that some individuals were not able to access the most preferred item. However, this was unlikely to have been a major issue as on some trials almost every member of the mob was feeding from the same container. Future studies could investigate the relationship between hierarchy position and food choice, and the effect of container size.

There was, in general, strong correspondence between adults' and juveniles' preferences. Meerkat pups learn food preferences from adults (Thornton, 2008a), and this result suggests that the juveniles in our study had acquired a lot of food preference information by their age. Thornton observed that pups initially declined to eat boiled eggs and documented the process of learning to eat eggs from adults. Consistent with this, we observed weaker preference for boiled eggs in juveniles than in adults. Where the two hierarchies diverged, there are a few possible explanations. One is that preference is to some degree idiosyncratic across individuals, and/or changes over maturation. Another is that juveniles have the same preference hierarchy as adults, but they were not consistently able to engage with their most preferred food because their access was blocked by the adults. In the current arrangement most, but not all, of the mob could comfortably fit around each food container. The relative contributions of these factors could be explored in future research, for example using larger containers and/or tracking food preference as meerkats develop.

In conclusion, this study developed and tested a brief, simple method for assessing food preference in a group of meerkats. Results indicated a clear preference hierarchy that reliably predicted which food the group would select on individual paired-choice trials. This hierarchy was shared by juveniles and adults including the dominant female. This approach might be used by zoo staff to efficiently assess food preference in group-housed, social species.

\section{ACKNOWLEDGMENTS}

The authors would like to acknowledge the Wellington Zoo Animal Care Teams for their help and support during this project. The authors would like to acknowledge Karen Fifield for providing feedback on this manuscript. The authors also acknowledge Associate Professor Jason Low for his input on initial project development and animal ethics application process.

\section{CONFLICT OF INTERESTS}

The authors declare that there are no conflict of interests.

\section{AUTHOR CONTRIBUTIONS}

Bridget W. Brox contributed to this work by planning the experiment, collecting data, data collation and analysis, and writing the first and final drafts of this manuscript. Katheryn Edwards contributed to this work by planning the experiment, collecting data, data collation, and providing specific feedback on the first and final drafts of this manuscript. Natasha A. Buist contributed to this work by planning the experiment, collecting data, data collation and analysis, and providing specific feedback on the first and final drafts of this manuscript. Anne C. Macaskill contributed to this work by planning the experiment, collecting data, data collation and analysis, and providing specific feedback on the first and final drafts of this manuscript.

\section{DATA AVAILABILITY STATEMENT}

The data that support the findings of this study are available from the corresponding author on reasonable request.

\section{ORCID}

Bridget W. Brox (D) https://orcid.org/0000-0001-5395-2185

\section{REFERENCES}

Addessi, E., Mancini, A., Crescimbene, L., Padoa-Schioppa, C., \& Visalberghi, E. (2008). Preference transitivity and symbolic 
representation in capuchin monkeys (Cebus apella). PLOS One, 3(6): e2414. https://doi.org/10.1371/journal.pone.0002414

Addessi, E., Stammati, M., Sabbatini, G., \& Visalberghi, E. (2005). How tufted capuchin monkeys (Cebus apella) rank monkey chow in relation to other foods. Animal Welfare, 14(3), 215-222. https:// www.researchgate.net/publication/233567906_How_tufted_ capuchin_monkeys_Cebus_apella_rank_monkey_chow_in_relation_ to_other_foods

Alligood, C. A., Dorey, N. R., Mehrkam, L. R., \& Leighty, K. A. (2017). Applying behavior-analytic methodology to the science and practice of environmental enrichment in zoos and aquariums. Zoo Biology, 36(3), 175-185. https://doi.org/10.1002/zoo.21368

Alvarez, M. R., \& Kravetz, F. O. (2009). Effect of ascorbic acid on food preference and consumption in captive capybaras (Hydrochoerus hydrochaeris). Brazilian Archives of Biology and Technology, 52(3), 593-600. https://doi.org/10.1590/s1516-89132009000300011

Bacon, E. S., \& Burghardt, G. M. (1983). Food preference testing of captive black bears. Bears: Their Biology and Management, 5, 102-105. https://www.researchgate.net/publication/239926243_Food_ Preference_Testing_of_Captive_Black_Bears

Bousquet, C. A. (2011). Group decision-making in meerkats (Suricata suricatta). University of Zurich. https://www.researchgate.net/ publication/225280055_Group_decision-making_in_meerkats_ Suricata_suricatta_-_PhD_thesis

Carter, S. K., Rosas, F. C. W., Cooper, A. B., \& Cordeiro-Duarte, A. C. (1999). Consumption rate, food preferences and transit time of captive giant otters Pteronura brasiliensis: Implications for the study of wild populations. Aquatic Mammals, 25(2), 79-90. https://www. researchgate.net/publication/250916167_Consumption_rate_food_ preferences_and_transit_time_of_captive_giant_otters_Pteronura_ brasiliensis_Implication_for_the_study_of_wild_populations

Clay, A. W., Bloomsmith, M. A., Marr, M. J., \& Maple, T. L. (2009). systematic investigation of the stability of food preferences in captive orangutans: Implications for positive reinforcement training. Journal of Applied Animal Welfare Science, 12(4), 306-313. https:// doi.org/10.1080/10888700903163492

Cunha, H. F., Carrijo, T. F., Prestes, A. C., Arruda, L. S., Rezende, P. B., Santos, T., \& Brandao, D. (2015). Food preference of giant anteater and collard anteater (Pilosa, Myrmecophagidae) regarding the termite defense strategies. Bioscience Journal, 31(1), 234-241. http://www. seer.ufu.br/index.php/biosciencejournal/article/view/23360/15894

Fernandez, E. J., Dorey, N. R., \& Rosales-Ruiz, J. (2004). A two-choice preference assessment with five cotton-top tamarins (Saguinus oedipus). Journal of Applied Animal Welfare Science, 7(3), 163-169. https://www. researchgate.net/publication/8217880_A_Two-Choice_Preference_ Assessment_With_Five_Cotton-Top_Tamarins_Saguinus_oedipus

Fisher, W., Piazza, C. C., Bowman, L. G., Hagopian, L. P., Owens, J. C., \& Slevin, I. (1992). A comparison of 2 approaches for identifying reinforcers for persons with severe and profound disabilities. Journal of Applied Behavior Analysis, 25(2), 491-498. https://www.ncbi.nlm.nih.gov/pmc/ articles/PMC1279726/

Gaalema, D. E., Perdue, B. M., \& Kelling, A. S. (2011). Food preference, keeper ratings, and reinforcer effectiveness in exotic animals: The value of systematic testing. Journal of Applied Animal Welfare Science, 14(1), 33-41. https://doi.org/10.1080/10888705.2011.527602

Hoppitt, W., Samson, J., Laland, K. N., \& Thornton, A. (2012). Identification of learning mechanisms in a wild meerkat population. PLOS One, 7(8): 42044. https://doi.org/10.1371/journal.pone.0042044

Jildmalm, R., Amundin, M., \& Laska, M. (2008). Food preferences and nutrient composition in captive white-handed gibbons, Hylobates lar. International Journal of Primatology, 29(6), 1535-1547. https://doi.org/10.1007/ s10764-008-9314-1

Kawata, K., \& Elsen, K. M. (1992). Nutritional intake and food preference in Hoffmann's sloth, Choloepus hoffmanni, in captivity. Zoologische Garten, 62(2), 65-74.
Lalremruati, P., \& Solanki, G. S. (2018). Nutrients availability and food preference in nursing stump-tailed monkey (Macaca arctoides) at Aizawl Zoological Park, Mizoram. Indian Journal of Animal Nutrition, 35(2), 224-230. file:///C:/Users/bridg/Downloads/80355-2041121-SM.pdf

Laska, M., Salazar, L. T. H., \& Luna, E. R. (2000). Food preferences and nutrient composition in captive spider monkeys, Ateles geoffroyi. International Journal of Primatology, 21(4), 671-683. https://www. sciencedirect.com/science/article/pii/S003193842030439X

Martin, A. L., Franklin, A. N., Perlman, J. E., \& Bloomsmith, M. A. (2018). Systematic assessment of food item preference and reinforcer effectiveness: Enhancements in training laboratory-housed rhesus macaques. Behavioural Processes, 157, 445-452. https://doi.org/10. 1016/j.beproc.2018.07.002

Mehrkam, L. R., \& Dorey, N. R. (2014). Is preference a predictor of enrichment efficacy in Galapagos tortoises (Chelonoidis nigra)? Zoo Biology, 33(4), 275-284. https://doi.org/10.1002/zoo.21151

Mehrkam, L. R., \& Dorey, N. R. (2015). Preference assessments in the zoo: Keeper and staff predictions of enrichment preferences across species. Zoo Biology, 34(5), 418-430. https://doi.org/10.1002/zoo. 21227

Moermond, T., \& Denslow, J. (1983). Fruit choice in neotropical birds: effects of fruit type and accessibility on selectivity. The Journal of Animal Ecology, 52, 407. https://doi.org/10.2307/4562

Naves, D. A. S., Carvalho, T. S. G., Zangeronimo, M. G., Saad, C. E. P., \& Scalon, J. D. (2017). Food preferences of cockatiel chicks (Nymphicus hollandicus) in captivity. Arquivo Brasileiro De Medicina Veterinaria E Zootecnia, 69(3), 683-686. https://www.researchgate.net/ publication/318313620_Food_preferences_of_cockatiel_chicks_ Nymphicus_hollandicus_in_captivity

Nowakowski, W. K., Remisiewicz, M., \& Kosowska, J. (2006). Food preferences of Glis glis (L.), Dryomys nitedula (Pallas) and Graphiurus murinus (Smuts) kept in captivity. Polish Journal of Ecology, 54(3), 369-378. https://www.academia.edu/2143525/Food_preferences_ of_Glis_glis_L_Dryomys_nitedula_Pallas_and_Graphiurus_murinus_ Smuts_kept_in_captivity

Rao, A., Range, F., Kadletz, K., Kotrschal, K., \& Marshall-Pescini, S. (2018). Food preferences of similarly raised and kept captive dogs and wolves. PLOS One, 13(9):0203165. https://doi.org/10.1371/journal. pone.0203165

Remis, M. J. (2002). Food preferences among captive western gorillas (Gorilla gorilla gorilla) and chimpanzees (Pan troglodytes). International Journal of Primatology, 23(2), 231-249. https://www.researchgate. net/publication/225231520_Food_Preferences_Among_Captive_ Western_Gorillas_Gorilla_gorilla_gorilla_and_Chimpanzees_Pan_ troglodytes

Roberts, D. T., \& Mitchell, L. A. (1998). Population structure, activity patterns and food preference in free-ranging Texas rat snakes at the Dallas Zoo. American Zoo and Aquarium Association Annual Conference Proceedings, 1998, 345-347. https://doi.org/10.1894/ 0038-4909-64.3-4.173

Ross-Gillespie, A., \& Griffin, A. S. (2007). Meerkats. Current Biology, 17(12), R442-R443. https://doi.org/10.1016/j.cub.2007.03.045

Salomonsson, C. (2011). Food preferences in captive meerkats (Suricata suricatta). (Independent thesis Advanced level (degree of Master (Two Years)) Student thesis). http://urn.kb.se/resolve?urn= urn:nbn:se:liu:diva-70120 DiVA database.

Steele, T. L., Butler, N. A., Segar, M. T., \& Olson, S. M. (1995). Preferences for food location and foraging requirements in white-handed gibbons. American Zoo and Aquarium Association Regional Conference Proceedings, 151-158. https://awionline.org/lab-animalsearch/steele-t-l-butler-n-segar-m-t-et-al-1995-preferences-foodlocation-and-foraging

Thompson, H., Riemer, S., Ellis, S. L. H., \& Burman, O. H. P. (2016). Behaviour directed towards inaccessible food predicts consumption: 
A novel way of assessing food preference. Applied Animal Behaviour Science, 178, 111-117. https://doi.org/10.1016/j.applanim.2016.02.008

Thornton, A. (2008a). Social learning about novel foods in young meerkats. Animal Behaviour, 76, 1411-1421. https://doi.org/10. 1016/j.anbehav.2008.07.007

Thornton, A. (2008b). Variation in contributions to teaching by meerkats. Proceedings of the Royal Society B-Biological Sciences, 275(1644), 1745-1751. https://doi.org/10.1098/rspb.2008.0268

Thornton, A., \& Malapert, A. (2009). Experimental evidence for social transmission of food acquisition techniques in wild meerkats. Animal Behaviour, 78(2), 255-264. https://doi.org/10.1016/j.anbehav. 2009.04.021

Unger, R., \& Schratter, D. (2000). Feeding preferences of short-eared elephant shrews (Macroscelides proboscideus) at the
Schoenbrunn zoological garden, Vienna, Austria. Zoologische Garten, 70(1), 60-69.

Zoidis, A. M., \& Markowitz, H. (1992). Findings from a feeding study of koala (Phascolarctos-cinereus-adustus) at the San Francisco Zoo. Zoo Biology, 11(6), 417-431. https://doi.org/10.1002/zoo.1430110608

How to cite this article: Brox, B. W., Edwards, K., Buist, N. A., \& Macaskill, A. C. (2021). Investigating food preference in zoo-housed meerkats. Zoo Biology, 1-10.

https://doi.org/10.1002/zoo.21640 